\title{
Association of Parents' Body Esteem and Body Mass Index with Children's Body Esteem and BMI: A Study from Turkey
}

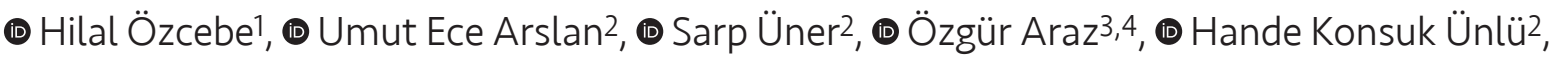 \\ (1) Mahmut Yardım1, (1) Nazmi Bilir5, (1) Terry T-K Huang6 \\ ${ }^{1}$ Hacettepe University Faculty of Medicine, Department of Public Health, Ankara, Turkey \\ ${ }^{2}$ Hacettepe University Institute of Public Health, Ankara, Turkey \\ 3 University of Nebraska Medical Center, College of Public Health, Omaha, USA \\ ${ }^{4}$ University of Nebraska - Lincoln, College of Business, Omaha, USA \\ ${ }^{5}$ Emeritus Professor of Public Health Institute, Turkey \\ 6University of New York, Graduate School of Public Health and Health Policy, Center for Systems and Community Design, New York, USA
}

\begin{abstract}
Aim: Childhood obesity is associated with psychosocial and medical comorbidities. Children affected by obesity have significantly lower selfesteem than children with normal weight, and families have an important role in the development of body image and body dissatisfaction. We aimed to examine the relationship between the body esteem of obese children and their parents' body esteem and weight status.

Materials and Methods: This study was carried out in Ankara, the capital city of Turkey, and was rolled out to 9 to 11-year-old children and their parents in 46 schools (2,066 parent-child dyads). The data were collected via parent and child questionnaires. Anthropometric measurements were conducted by the project team. Four different logistic regression models were performed separately; body esteem and Body Mass Index (BMI) for fathers and sons, fathers and daughters, mothers and sons, and mothers and daughters.

Results: Mothers obesity was associated with their daughters' and their sons' obesity status. Fathers' obesity status appears to be positively associated with their sons' status only but not their daughters'. The body esteem of the obese boys was adversely affected only by their own BMI in the models with their fathers and mothers. Compared to boys, girls were affected adversely by their own BMI, their body esteem, and their mothers' and fathers' body esteem.
\end{abstract}

Conclusion: A strong association between both the mothers' and fathers' role in the body esteem of daughters was found. Further research should be conducted to better understand the socio-cultural dynamics that may be unique to the development of childhood obesity.

Keywords: BMI, body esteem, childhood obesity, parental relations, daughter, sons, Turkey

\section{Introduction}

The prevalence of childhood obesity has increased in the last three decades worldwide. This poses a serious public health problem in both developing and developed countries (1). The prevalence of obesity also increased from 8.3 to 9.9\% from 2013 to 2016 among 7-8-year-old children, and it is considered as an emergent public health problem in Turkey (2).

Obesity in childhood increases the risk of obesity in adulthood, and is associated with psychosocial and medical comorbidities (3). Children affected by obesity have significantly lower self-esteem than children with 
normal weight. $(4,5)$. Body esteem is a measure of body image that includes at least three aspects: feelings about one's general appearance, feelings about one's weight, and evaluations attributed to others about one's body (6). Children with low body esteem consider themselves "stupid", "ugly", "unhappy", "less competent", "sloppy", "lazy" and/or "socially isolated", and they usually lack selfdiscipline, motivation and personal control (7).

Families play an important role in the development of body image and body dissatisfaction among children. In particular, past research has shown that girls' identification with their mothers is a strong factor in their development, including the formation of gender-role identity, body image, and self-esteem, as mothers serve as both role models and sources of information and guidance (8). Perez et al. (9) found that daughters' thin body ideal was significantly affected by their mothers' body dissatisfaction. By the same token, mothers' self-objectification can also influence their daughters' self-objectification. On the other hand, research on the role of fathers into this issue is limited (10). In contrast to general expectation, Johannsen et al. (11) showed that fathers can have higher concerns about their daughters' weight in the future, more so than their sons'.

The roles of the mothers' and fathers' body esteem and weight status on their children's body esteem have not been studied previously in Turkey. In the present study, we examined these relationships in a relatively large population-based sample of parent-child dyads in Ankara, Turkey.

\section{Materials and Methods}

This research is a part of Childhood Obesity Study in the metropolitan area of Ankara (COSA) (12). The surveys were rolled out to grade 4 children (aged 9-11 years) and their parents in 46 schools $[15$ schools were from low socioeconomic status (SES), 17 schools from medium SES, and 14 schools from high SES]. The schools were selected from all SES by using probability proportional-to-size methodology in order to match the general population. The detailed study protocol can be found in the article by Yardım et al. (12). Parental questionnaires were sent to parents by their corresponding schools, and they were returned with an informed consent form to the schools. Children consented to the study and completed the questionnaires under the supervision of the research team and teachers in the schools. Anthropometric measurements were conducted with personal privacy by the research team. The study was approved by the Ministry of National Education and the Non-interventional Clinical Research Ethics Board Hacettepe University, Ankara, Turkey (GO 14-429-07).

\section{Measurements}

The body esteem scale was developed for adolescents and adults by Mendelson et al. (6) and includes 23 items. It consists of three dimensions to gauge a respondent's feelings about his/her body: Appearance (Cronbach's alpha= 0.92), Attribution (Cronbach's alpha $=0.81$ ) and Weight (Cronbach's alpha $=0.94$ ). Tests of validity and reliability of the scale were performed in children and adults in COSA. The results were found for Appearance (Cronbach's alpha=0.76) for Attribution (Cronbach's alpha= 0.69) and for Weight (Cronbach's alpha= 0.85). According to confirmatory factor analysis (CFA), the results showed a root mean square error of approximation (RMSEA) $=0.039$ (Pclose <1.00), chi-square to $\mathrm{df}$ ratio $(C M I N / d f)=3.406(p<0.001)$, SRMR= 0.040, and goodness-of-fit index $(\mathrm{GFI})=0.979$. Test-retest analysis presented the following statistics: Appearance (Spearman's $r=0.68$ ), Attribution (Spearman's $r=0.57$ ) and Weight (Spearman's $r=0.68$ ) for children. CFA was conducted with the 12-item three-factor version for adults. Results of CFA were obtained as RMSEA $=0.067$ (Pclose $<1.00$ ), and $\mathrm{GFI}=0.959$. The test-retest reliability of the BE scale has Appearance (Spearman's $r=0.59$ ), Attribution (Spearman's $r=0.72$ ) and Weight (Spearman's $r=0.68$ ), for adults, respectively. We presented the total scores of the body esteem scale in the analyses section.

Height and weight measurements of the children were conducted to assess the children's Body Mass index (BMI). BMI-for-age was calculated using the WHO ANTHRO Plus program and classified as underweight, normal, overweight or obese. The BMI of the mothers and fathers were calculated based on their self-reported weight and height and they were classified based on standard adult cut-offs (13). Only one parent (either the mother or father) served as the primary respondent to the questionnaire for each student.

\section{Statistical Analysis}

The Kruskal-Wallis test was used to compare scaled variables across more than two independent groups. Pairwise comparisons were performed using Dunn's test. Pearson's chi-square test was used to compare proportions. We combined underweight and normal weight into one group and compared it to the overweight and obese groups. The total body esteem score in children was the outcome measure. Receiver operating characteristic (ROC) curve analyses were performed to evaluate the cut-off point for the total body esteem score (14). The best cut-off point of total score for boys and girls was obtained as 36 . Individual scores lower than the cut-off point were classified as low 
body esteem; and scores higher than the cut-off point were classified as high body esteem (15). The parents' body esteem scores were treated as a continuous variable in our analyses. Analyses were performed using SPSS version 23.0 (Chicago, IL) with alpha set as $\mathrm{p}<0.05$.

Logistic regression models were used to examine the risk of low body esteem among children in relation to their own weight status, their parents' weight status and their parents' body esteem. Four separate logistic regression models were performed by using the father-son, fatherdaughter, mother-son, and mother-daughter data sets. SES status (reference is high SES), child obesity status (reference is normal BMI), the relevant parent's obesity status (reference is normal BMI), the relevant parent's body esteem (corresponding dimension or total score) were included as the main effects in relation to the low body esteem of children. In the regression model, those children having higher scores than the cut-off point were coded as " 0 " which means "having high body esteem" and the ones having lower scores than the cut-off point were coded as "1" which represents "having low body esteem".

\section{Results}

The study sample included 2,066 parent-child dyads. The sample included $53.1 \%$ girls and $46.9 \%$ boys. $53.2 \%$ of children were from low SES, $34.6 \%$ from middle SES and $12.1 \%$ from high SES. The education level of the fathers was higher than the mothers; $60.3 \%$ of fathers vs. $47.9 \%$ of mothers had high school or higher degree education levels $(p<0.001)$. Most of the fathers were employed $(95.5 \%)$ while the percentage of employment among the mothers (33.0\%) was lower $(p<0.001)$ The rates of being overweight or obese among mothers were $34.8 \%$ and $16.1 \%$, respectively; these percentages in fathers were $50.5 \%$ and $19.6 \%$, respectively. The rates of the child being overweight or obese were $21.2 \%$ and $14.6 \%$ respectively $(12)$.

Table I shows the comparison of children's weight status with their mothers and fathers. Results showed that the mothers' obesity was associated with their daughters' and their sons' obesity status $(p<0.001, p<0.001)$. However, the fathers' obesity status appears to be positively associated with their sons' status only $(p<0.001)$, as it was not found to be statistically associated with their daughters'.

Figure 1 shows that there is a statistically significant negative correlation between BMI and body esteem among girls, boys, mothers and fathers, suggesting that selfesteem increases as BMI decreases ( $p<0.001$ for all four group).
The body esteem of boys was significantly negatively associated with their own BMI $(p<0.001)$ when a logistic regression model was used to examine the association between mothers and their boys. Body esteem of the obese boys was 9.01 times lower, compared to normal weight boys. For girls, they were affected by their mothers' body esteem score $(p=0.001)$ in addition to their own obesity status $(p<0.001)$ in the model that examined the association between mothers and their daughters. Overweight girls had 5.32 times and obese girls had 16.88 times lower body esteem than girls who had normal BMI, and the body esteem of girls increased as the body esteem of their mothers increased (Table II).

The body esteem of boys was adversely associated with their own BMI $(p=0.006)$ in the model examining the association between fathers and their boys. The body esteem of the overweight and obese boys were 3.08 and 4.55 times lower than the body esteem score of normal weight boys respectively. In this model, there was a doseresponse relationship observed between girls' total body esteem and their BMI status $(p<0.001)$ for fathers and their daughters. Overweight and obese girls have lower body esteem (4.96 and 9.92, respectively) compared to normal weight girls. The other result we observed was that the body esteem of girls increased as the body esteem of their fathers increased (Table III).

\section{Discussion}

To the best of our knowledge, this is the first study in Turkey to explore the association between mothers' and fathers' body esteem with their daughters and sons. We found a significant relationship between mothers' and fathers' body esteem with the body esteem of their daughters. For both boys and girls, their body esteem was significantly associated with their own BMI, suggesting that among Turkish children, high BMI may have deleterious psychological effects.

With the increasing epidemic of obesity in Turkey (2), there is a great need for public health policies to address the psychosocial sequelae of obesity among children. In the COSA study, we have previously reported that the prevalence of obesity among 10-year-old children was $14.6 \%$, which is much higher than prior studies and the most recent estimates of national prevalence in Turkey (12). This suggests that children in the larger urban areas in the country may be at higher risk for obesity-related comorbidities $(1,3)$. Çolpan et al. (16) found that children affected by obesity had lower self-esteem than children who were not affected by obesity. They also found a 
relationship between self-esteem and other emotional and behavioral problems. Our results corroborate the findings of their study which also used a population-based sample from Ankara. We also found a statistically significant negative correlation between $\mathrm{BMI}$ and body esteem for girls and boys; and showed their self-esteem increased as BMI decreased. This negative correlation is consistent with prior research in the United States and Europe $(3-5,17)$.

Obesity in children can be affected by parental obesity status, suggesting that family dynamics, including family lifestyle, attitudes and perceptions on obesity are important determinants for obesity in childhood. Eating habits, family and environmental factors serve as targets of prevention and treatment interventions in many studies (9).

In our study, fathers' weight status and their sons' weight status were correlated, similar to prior research $(9,18)$. However, the same was not true between fathers and daughters, in contrast with the study by Power et al. (19). It is possible that the effect of the same-gender parents (i.e. father/son or mother/daughter) may be stronger in the cultural context (9). In Turkey, the main responsibilities of the mothers are "cooking" and "taking care of children" and fathers have the main responsibility for providing the income in the family (20). It is likely that mothers have more influence on their children than fathers in Turkish communities in terms of weight-related outcomes.
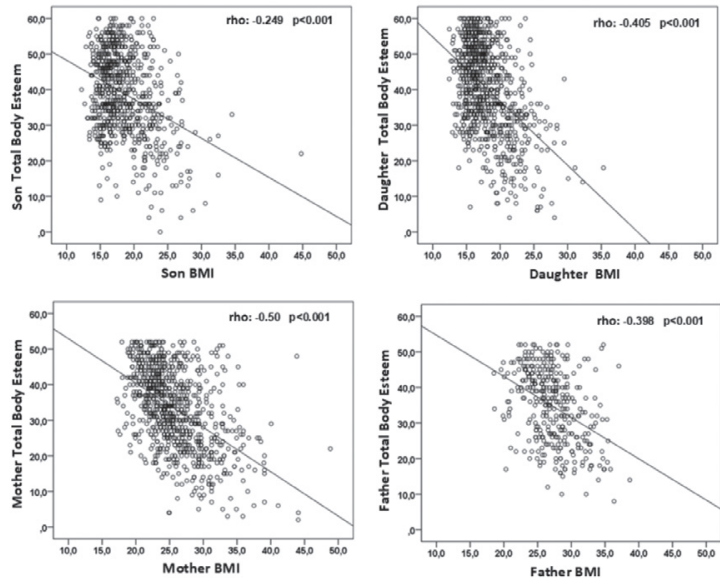

Figure 1. Correlation diagram BMI by self-esteem in children and parents

BMI: Body mass index

Table I. The percentage distribution of children' body mass index by families' body mass index

\begin{tabular}{|c|c|c|c|c|c|c|}
\hline & \multirow[b]{2}{*}{ BMI } & \multicolumn{5}{|l|}{ BMI } \\
\hline & & $\begin{array}{l}\text { Underweight } \\
\text { and normal }\end{array}$ & Overweight & Obese & Total & p \\
\hline & & \multicolumn{5}{|l|}{ Daughters } \\
\hline \multirow[t]{4}{*}{ Mother } & Underweight and normal & 67.7 & 25.1 & 7.2 & 279 & \multirow{4}{*}{$<0.001$} \\
\hline & Overweight & 59.2 & 26.7 & 14.1 & 206 & \\
\hline & Obese & 47.1 & 27.1 & 25.9 & 85 & \\
\hline & Total & 61.6 & 26.0 & 12.5 & 570 & \\
\hline \multirow[t]{5}{*}{ Father } & Underweight and normal & 77.3 & 18.2 & 4.5 & 66 & \multirow{4}{*}{0.335} \\
\hline & Overweight & 70.2 & 18.2 & 11.6 & 121 & \\
\hline & Obese & 75.0 & 21.2 & 3.8 & 52 & \\
\hline & Total & 73.2 & 18.8 & 7.9 & 239 & \\
\hline & & \multicolumn{5}{|l|}{ Sons } \\
\hline \multirow[t]{4}{*}{ Mother } & Underweight and normal & 62.0 & 18.8 & 19.2 & 250 & \multirow{4}{*}{$<0.001$} \\
\hline & Overweight & 62.1 & 23.7 & 14.1 & 177 & \\
\hline & Obese & 51.2 & 11.6 & 37.2 & 86 & \\
\hline & Total & 309 & 99 & 105 & 513 & \\
\hline \multirow[t]{4}{*}{ Father } & Underweight and normal & 77.5 & 12.5 & 9.9 & 71 & \multirow{4}{*}{$<0.001$} \\
\hline & Overweight & 47.8 & 30.4 & 21.7 & 115 & \\
\hline & Obese & 55.3 & 10.5 & 34.2 & 38 & \\
\hline & Total & 58.5 & 21.4 & 20.1 & 224 & \\
\hline
\end{tabular}


Unfortunately, we could not ask about gender roles and parenting behaviors in terms of mothers vs fathers in our study, but this issue warrants further research. More research is needed to understand the underlying cultural mechanisms of the relations between paternal and childhood obesity in different countries.

The strong relationship between mothers' body esteem and their daughters also corroborates with previous studies $(9,21)$. Cooley et al. $(22)$ found that mothers have a strong influence on their daughters' lifestyle and behaviors such as eating and physical activity, and also their feelings and attitudes towards themselves. It is also known that the mother-daughter relationship affects the daughter's body perception. Since parents are role-models for their children, mothers worrying about their weight and their body image could also become negative role-models for their daughters (23). In light of our findings, psychological support targeting mothers may be particularly important in the design of obesity interventions in Turkey.

We also found a significant association between fathers' and daughters' body esteem. The father's role in childhood obesity has only begun to be discussed in recent years, but the literature does not specifically include relationship between the body esteem of obese fathers and their obese daughters (24). Sagkal et al. (25) showed that the fatherdaughter relationship is related to the well-being of the daughters in the Turkish population. Our findings suggest that family interventions in Turkey could potentially benefit from the inclusion of fathers as well, at least with regard to their daughters' weight-related outcomes.

Results showed that the body esteem of sons was not affected by their mothers' or fathers' body esteem (the sons' own weight status was the significant correlate of their body esteem). Studies show that girls are more affected by parental body esteem and body image than boys (8-10).

Weinberger et al. (26) showed that, in general, women reported more dissatisfaction with their bodies than men, but some studies also show that men affected by obesity have lower body esteem than those who are not affected by obesity. In our study, we found a statistically significant negative correlation between BMI and body esteem among mothers, but this relationship was not statistically significant among fathers. Lengerke et al. (27) discussed that the lack of awareness on overweight and obesity status among low socioeconomic status individuals can also cause lower body dissatisfaction; Bibiloni et al. (28) mentioned that cultural factors, such as acceptance of body image,

Table II. Impact of socio-economic status, body mass index, and mothers' body esteem on their children' body esteem

\begin{tabular}{|c|c|c|c|c|c|c|c|c|}
\hline & \multicolumn{4}{|c|}{ Sons' body esteem } & \multicolumn{4}{|c|}{ Daughters' body esteem } \\
\hline & \multirow[b]{2}{*}{$\mathbf{p}$} & \multirow[b]{2}{*}{$\operatorname{Exp}(B)$} & \multicolumn{2}{|c|}{$95 \% \mathrm{Cl}$} & \multirow[b]{2}{*}{$p$} & \multirow[b]{2}{*}{$\operatorname{Exp}(B)$} & \multicolumn{2}{|c|}{$95 \% \mathrm{Cl}$} \\
\hline & & & Lower & Upper & & & Lower & Upper \\
\hline School SES & 0.38 & & & & 0.16 & & & \\
\hline \multicolumn{9}{|l|}{ High (reference) } \\
\hline Middle & 0.19 & 1.71 & 0.76 & 3.86 & 0.06 & 2.04 & 0.95 & 4.37 \\
\hline Low & 0.49 & 1.33 & 0.58 & 3.05 & 0.30 & 1.49 & 0.69 & 3.19 \\
\hline Children BMI & $<0.001$ & & & & $<0.001$ & & & \\
\hline \multicolumn{9}{|l|}{ Normal (reference) } \\
\hline Overweight & 0.09 & 1.66 & 0.91 & 3.04 & $<0.001$ & 5.32 & 3.11 & 9.08 \\
\hline Obese & $<0.001$ & 9.01 & 4.49 & 18.07 & $<0.001$ & 16.88 & 6.66 & 42.79 \\
\hline Mother BMI & 0.66 & & & & 0.85 & & & \\
\hline \multicolumn{9}{|l|}{ Normal (reference) } \\
\hline Overweight & 0.99 & 1.00 & 0.54 & 1.84 & 0.95 & 0.98 & 0.55 & 1.74 \\
\hline Obese & 0.41 & 0.69 & 0.29 & 1.66 & 0.60 & 0.79 & 0.34 & 1.86 \\
\hline Mother body esteem score & 0.75 & 0.99 & 0.96 & 1.02 & 0.001 & 0.95 & 0.93 & 0.98 \\
\hline Constant & 0.053 & 0.29 & & & 0.66 & 0.77 & & \\
\hline
\end{tabular}

Note. Parental body esteem variable corresponds to the specific dimension or total score among children, BMI: Body Mass index, CI: Confidence interval, SES: Socioeconomic status 
Özcebe et al.

Parents and Children; Body Esteem and Obesity

\begin{tabular}{|c|c|c|c|c|c|c|c|c|}
\hline & \multicolumn{4}{|c|}{ Sons' body esteem } & \multicolumn{4}{|c|}{ Daughters' body esteem } \\
\hline & \multirow[b]{2}{*}{$\mathbf{p}$} & \multirow[b]{2}{*}{$\operatorname{Exp}(B)$} & \multicolumn{2}{|l|}{$95 \% \mathrm{Cl}$} & \multirow[b]{2}{*}{$\mathbf{p}$} & \multirow[b]{2}{*}{$\operatorname{Exp}(B)$} & \multicolumn{2}{|l|}{$95 \% \mathrm{Cl}$} \\
\hline & & & Lower & Upper & & & Lower & Upper \\
\hline School SES & 0.74 & & & & 0.11 & & & \\
\hline \multicolumn{9}{|l|}{ High (reference) } \\
\hline Middle & 0.99 & 1.00 & 0.28 & 3.55 & 0.24 & 0.52 & 0.17 & 1.55 \\
\hline Low & 0.64 & 0.73 & 0.19 & 2.70 & 0.040 & 0.26 & 0.07 & 0.94 \\
\hline Children BMI & 0.006 & & & & $<0.001$ & & & \\
\hline \multicolumn{9}{|l|}{ Normal weight (reference) } \\
\hline Overweight & 0.030 & 3.08 & 1.11 & 8.55 & 0.001 & 4.96 & 1.92 & 12.80 \\
\hline Obese & 0.003 & 4.55 & 1.67 & 12.34 & 0.008 & 9.26 & 1.80 & 47.46 \\
\hline Father BMI & 0.30 & & & & 0.20 & & & \\
\hline \multicolumn{9}{|l|}{ Normal (reference) } \\
\hline Overweight & 0.13 & 0.48 & 0.19 & 1.24 & 0.43 & 0.71 & 0.30 & 1.67 \\
\hline Obese & 0.29 & 0.50 & 0.13 & 1.83 & 0.07 & 0.35 & 0.11 & 1.11 \\
\hline Father body esteem score & 0.38 & 0.98 & 0.94 & 1.02 & 0.024 & 0.95 & 0.91 & 0.99 \\
\hline Constant & 0.86 & 1.19 & & & 0.07 & 5.78 & & \\
\hline
\end{tabular}

can also vary among countries. We could not explain the differences between men and women in this study, however research on adults can help to answer the body esteem differences between men and women by investigating social and cultural factors.

\section{Study Limitations}

This study also has some limitations. There can be other possible explanations to describe the relationship between parental BMI, parental body esteem, and children's body esteem. More contextually rich research including the use of qualitative or mixed methods will be helpful to investigate the underlying mechanisms. Our study may not be generalizable to other populations in Turkey.

\section{Conclusion}

In conclusion, the family has a crucial role in the physical, mental and social development of children. Our study highlights the need for more evidence-based approaches to help families improve their children's health and quality of life. We found strong evidence that both mothers and fathers have a role to play in the body esteem of daughters, suggesting a whole family approach may be essential so as not to lose sight of the importance of fathers. Our research adds another dimension to the national strategy for obesity by shedding light on potential family levers in the design of prevention and treatment interventions. As obesity continues to rise in emerging economies worldwide, countries such as Turkey are in critical need of culturally tailored intervention strategies. Our research adds to the emerging literature and should inform obesity prevention and control programs and policies in Turkey.

\section{Funding}

The project (TUA-2015-5521) was financed by the Scientific Research Projects Coordination Unit of Hacettepe University and by the University of Nebraska Office of the President as a strategic initiative.

\section{Acknowledgement}

The University of Nebraska College of Public Health also provided research staff capacity in-kind. We thank the Turkish Ministry of National Education. students and staff from Hacettepe University Institute of Public Health. and schools and families across Ankara for facilitating this study.

\section{Ethics}

Ethics Committee Approval: The study was approved by the Ministry of National Education and the non- 
interventional Clinical Research Ethics Board Hacettepe University, Ankara, Turkey (CO 14-429-07).

Informed Consent: They were returned with an informed consent form to the schools.

Peer-review: Externally peer-reviewed.

\section{Authorship Contributions}

Concept: H.Ö., U.E.A., S.Ü., Ö.A., H.K.Ü., M.Y., N.B., T.T.H., Design: H.Ö., U.E.A., S.Ü., Ö.A., H.K.Ü., M.Y., N.B., T.T.H., Data Collection or Processing: H.Ö., U.E.A., S.Ü., Ö.A., H.K.Ü., M.Y., N.B., T.T.H, Analysis or Interpretation: H.Ö., U.E.A., H.K.Ü., T.T.H., Literature Search: H.Ö., U.E.A., S.Ü., Ö.A., H.K.Ü., M.Y., N.B., T.T.H., Writing: H.Ö., U.E.A., Ö.A.

Conflict of Interest: No conflict of interest was declared by the authors.

Financial Disclosure: The authors declared that this study received no financial support.

\section{References}

1. NCD Risk Factor Collaboration (NCD-RisC). Worldwide trends in body-mass index, underweight, overweight, and obesity from 1975 to 2016: a pooled analysis of 2416 population-based measurement studies in 128.9 million children, adolescents, and adults. The Lancet 2017; 390:2627-42.

2. Özcebe H, Yardım MS, Bağcı Bosi T, Yardım N. Turkey Childhood Obesity Surveillance Intitiative (COSI-TUR)- 2006. Ministry of Health General Directorate of Public Health, Ministry of National Education, WHO Europe. Ankara: Ministry of Health Publication Number: 1080, 2017.

3. Gibson $L Y$, Allen $K L$, Davis E, Blair E, Zubrick SR, Byrne SM. The psychosocial burden of childhood overweight and obesity: Evidence for persisting difficulties in boys and girls. Eur J Pediatr 2017; 176:925.

4. Rankin J, Matthews L, Cobley S, et al. Psychological consequences of childhood obesity: Psychiatric comorbidity and prevention Adolescent Health. Medicine and Therapeutics 2016; 7:125-146.

5. Ratcliffe D, Ellison N. Obesity and internalized weight stigma: a formulation model for an emerging psychological problem. Behav Cogn Psychother 2015; 239-52.

6. Mendelson BK, Mendelson MJ, White DR. Body-esteem scale for adolescents and adults. J Pers Assess 2001; 76:90-106.

7. Puhl RM, Brownell KD. Confronting and coping with weight stigma: An investigation of overweight and obese Adults. Obesity 2006; 14:1802-15

8. Usmiani S, Daniluk J. Mothers and their adolescent daughters: Relationship between self-esteem, gender role identity, body image. J Youth Adolesc 1997; 26:45-62.

9. Perez-Pastor EM, Metcalf BS, Hosking J, Jeffery AN, Voss LD, Wilkin TJ. Assortative weight gain in mother-daughter and father-son pairs: an emerging source of childhood obesity. Longitudinal study of trios (EarlyBird 43). Int I Obes 2009; 33:727-35.

10. Hopper LN. Fathers are critical to understanding childhood obesity. Int J Fam Commun Med 2017; 1:41-2.
11. Johannsen DL, Johannsen NM, Specker BL. Influence of parents' eating behaviors and child feeding practices on children's weight status. Obesity 2006; 14:431-9.

12. Yardım M, Ozcebe $H$, Araz OM, et al. Prevalence of childhood obesity and related parental factors in Ankara, Turkey. The EMHJ 2019; 25:374-84.

13. WHO 2018. WHO AnthroPlus for personal computers Manual: Software for assessing growth of the world's children and adolescents, Geneva, 2009.

14. Kleinbaum DG, Klein M. Logistic regression, A self-learning. New York: Springer, 2010.

15. Beoeck JD, Brestoff JR. Epidemiology: Principles and practical guidelines. Dordrecht: Springer, 2013.

16. Çolpan M, Eray Ş, Eren E, Vural AP. Perceived expressed emotion, emotional and behavioral problems and self esteem in obese adolescents: A case-control study. I Clin Res Pediatr Endocrinol 2018; May 23.

17. Gruber KJ, Haldeman LA. Using the family to combat childhood and adult obe $\neg$ sity. Prev Chronic Dis 2009; 6:1-10.

18. Bronphy S, Ress A, Knox G, Baker I, Thomas NE. Child fitness and father's bmı are Important factors in childhood obesity: A school based cross-sectional study. Plos One 2012; 7:36597.

19. Power RF, Power B, O'Gorman CS. A comparison of perceived and measured paternal weight and bmı, and relationship to weight and BMI of his children. Ir Med I 2018; 9;111:686.

20. Republic of Turkey Ministry of Family and Social Affair. Family Research in Turkey, 2016.

21. Birch LL, Faith MS, Francis LA, Scanlon KS, Sherry B. Parent-child feeding strategies and their relationship to child eating and weight status. Obesity Re-search 2004; 12:1711-22.

22. Cooley E, Toray T, Wang MC, Valdez NN. Maternal effects on daughters' eating pathology and body image. Eating Behaviors 2008; 9:52-61.

23. Ogden /, Steward ). The role of the mother-daughter relationship in explaining weight concern. Int J Eat Disord 2000; 28:78-83.

24. Walsh $A D$, Hesketh KD, van der Pligt $P$, Cameron A), Crawford D, Campbell KJ. Fathers' perspectives on the diets and physical activity behaviours of their young children. PLoS ONE 2017; 12:0179210.

25. Sagkal AS, Özdemir Y, Koruklu N. Direct and indirect effects of father-daughter relationship on adolescent girls' psychological outcomes: The role of basic psychological need satisfaction. J Adolesc, 2018; 68;32-9.

26. Weinberger NA, Kersting A, Riedel-Heller SG, Luck-Sikorski C. Body dissatisfaction in individuals with obesity compared to normal-weight individuals: A systematic review and metaanalysis. Obes Facts 2016; 9:424-41.

27. Lengerke T, Meilck A, KORA study group. Body weight dissatisfaction by socioeconomic status among obese, preobese and normal weight women and men: results of the crosssectional KORA Augsburg S4 population survey. BMC Public Health 2012; 12:342.

28. Bibiloni M, Coll JLI, Pich J, Pons A, Tur JA. Body image satisfaction and weight concerns among a Mediterranean adult population. Bibiloni et al. BMC Public Health 2017; 17:39. 